\title{
La Carta Magna mexicana en su centenario y el constitucionalismo Latinoamericano. Notas de un estudio comparado*
}

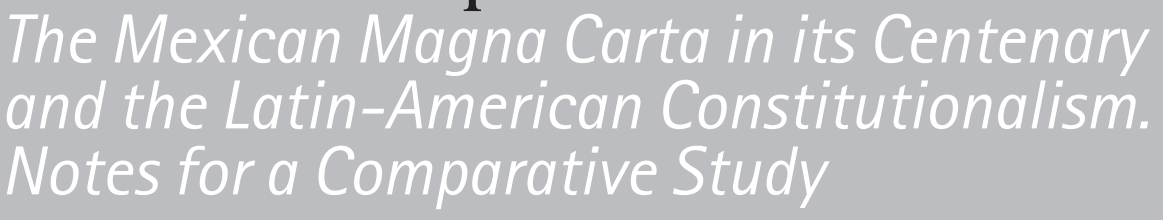

\section{Carlos Manuel Villabella Armengol**}

\section{RESUMEN}

En América Latina el derecho constitucional ha evolucionado con fragilidad. En la actualidad la región presenta un constitucionalismo renovado. Trece paises promulgaron cartas magnas en las últimas cuatro décadas. De éstas, las redactadas a finales de los años noventa contornearon un nuevo paradigma rupturista con los cánones del derecho decimonónico. En este entorno, la ley fundamental mexicana resalta por su vigencia centenaria y continuismo institucional. En este artículo, analizo al texto de 1917 desde la perspectiva del derecho comparado latinoamericano. La pregunta que guía el estudio es: ise ha desarrollado el constitucionalismo mexicano en el mismo tenor que el derecho constitucional de América Latina?

PALABRAS CLAVE: Derecho constitucional comparado, constitucionalismo latinoamericano, centenario de la Constitución de México.

\begin{abstract}
In Latin America the Constitutional Law has evolved with fragility. At present, the region presents a renewed constitutionalism. Thirteen countries has promulgated magna carta over the past four decades; of these, those written at the end of the nineties defined a new innovative paradigm that breaks the canons of the nineteenth-century law. In this environment, the Mexican Basic Law stands out for its hundredyear-old validity and institutional continuism. In this article, I analyze the text of 1917 from the perspective of the Latin-American comparative law. The question that guides the study is: has the Mexican constitutionalism developed along the same lines as the constitutional law of Latin America?
\end{abstract}

KEY WORDS: Comparative constitutional law, Latin-American constitutionalism, Centenary, Constitution of Mexico.

\footnotetext{
* Artículo recibido el 26 de febrero de 2016 y aceptado para su publicación de abril de 2016.

** Coordinador del Programa de Doctorado en Derecho del Centro de Ciencias Jurídicas de Puebla, México. (cavillabella84@gmail.com).
} 


\section{SUMARIO}

1. La etapa de inercia en el derecho constitucional de Latinoamérica

2. Nuevo constitucionalismo en la región

3. La Constitución de 1917, documento sui generis

4. La Carta Magna mexicana a la luz del derecho comparado de América Latina

5. Epílogo

\section{La etapa de inercia en el derecho constitucional de Latinoamérica}

En el mapa constitucional contemporáneo de Latinoamérica se aprecian cuatro ítems en relación con la data de las constituciones: los textos promulgados hasta la medianía del siglo xx: México (1917), Costa Rica (1949), Uruguay (1966), Panamá (1972); los documentos redactados por los gobiernos militares en la década del ochenta: Chile (1980), Honduras (1982), El Salvador (1983), Guatemala (1985); las leyes fundamentales creadas en las últimas décadas de la centuria anterior, algunas de ellas como efecto de la posdictadura: Nicaragua (1987), Brasil (1988), Colombia (1991), Paraguay (1992), Perú (1993), Argentina (1994); y las constituciones gestadas en el siglo xxi: Venezuela (1999), Ecuador (2008) y Bolivia (2009).

Las constituciones del primer grupo son documentos breves que se ciñeron fundamentalmente a organizar el poder político público y refrendar los derechos ciudadanos. Con posterioridad, las reformas actualizaron los textos e introdujeron nuevas instituciones. La Constitución de Costa Rica se redactó por una constituyente convocada por un gobierno provisional que adoptó el nombre de Junta Fundadora de la Segunda República. La asamblea elaboró el texto sobre el prototipo de la Constitución de 1871. Desde su promulgación, ha tenido 57 reformas. El texto de Uruguay, aprobado mediante plebiscito, se suspendió en 1973 por un golpe militar y recobró vigencia en 1985. Reinstauró la forma de gobierno presidencial con algunos elementos novedosos, luego de la experiencia de un modelo de gobierno convencional.

La ley de leyes de Panamá la redactó la Asamblea Nacional de Representantes de Corregimientos, convocada por la Junta Provisional de Gobierno conformada tras el golpe de estado de octubre de 1968. Este evento desencadenó un proceso de transformaciones sociales que explica el matiz de algunos contenidos del texto: reconoció la identidad de las comunidades indígenas, refrendó normas 
reguladoras de la seguridad y asistencia social, se pronunció por la protección del medio ambiente y el desarrollo de políticas agrarias, y estableció la responsabilidad del Estado en la orientación de la economía nacional.

Las constituciones emitidas en los años ochenta las redactaron los gobiernos militares como puente hacia a la apertura democrática. El texto de Chile se aprobó mediante plebiscito en septiembre de 1980. Entró en vigor parcialmente en 1981 y de manera integral en 1990. Los documentos de Honduras, El Salvador y Guatemala los gestaron asambleas convocadas y monitoreadas por las dictaduras.

Estas constituciones presentaron las siguientes novedades: introdujeron la figura del Ombudsman para la defensa de los derechos humamos, incluyeron artículos dedicados al orden económico y refrendaron derechos sociales. Asimismo, marcaron un giro en el control difuso de constitucionalidad predominante en la región al refrendar órganos de control concentrado o semiespecializado, los que ya se habían acogido en algunos países con anterioridad pero con una existencia efímera o poco efectiva. Iniciaron también la renovación de la forma de gobierno presidencial, tendencia que continuó evolucionando en las constituciones de los siguientes años.

Durante este periodo, el constitucionalismo latinoamericano estuvo en inercia, sin transformaciones sustanciales, reproduciendo el modelo constitucional liberal decimonónico que en América Latina tuvo influencia hasta bien entrado el siglo xx. ${ }^{1}$

\section{Nuevo constitucionalismo en la región}

Las cartas magnas promulgadas en las últimas décadas de la centuria anterior introdujeron cláusulas e instituciones provenientes de la doctrina europea, asumidas con el propósito de modernizarlas y propender a la estabilidad democrática y la vigencia de los derechos humanos. Así, el constitucionalismo europeo se convirtió en referente para la región, en el espejismo de que haciendo ingeniería constitucional se resolverían los rezagos formales y se transformaría la constitución material.

Muchos de los injertos constitucionales resultaron inoperantes, pues no se ajustaban al contexto cultural de la región o se enfrentaban al rechazo de los poderes constituidos. A pesar de ello, el momento marcó el inicio de un nuevo

\footnotetext{
${ }^{1}$ He desarrollado esta idea en Villabella Armengol, Carlos Manuel. "El derecho constitucional del siglo xxı en América Latina: entre la osmosis y un nuevo paradigma", Revista El Otro Derecho, No. 48, Colombia, Instituto Latinoamericano de Servicios Alternativos,2014, pp. 85-113.
} 
constitucionalismo ${ }^{2}$ regional desarrollado en las coordenadas del neoconstitucionalismo europeo. ${ }^{3}$ Ello rompió el inmovilismo que durante décadas reprodujo las fórmulas del constitucionalismo clásico y generó un proceso de reflexión sobre las problemáticas nacionales. De estas circunstancias germinaría un pensamiento constitucional crítico y original: "se anunciaba el fin de una era constitucional nominalista y poco original y del inicio de nuevas luces en el constitucionalismo latinoamericano [...] cambios que pronosticaban la conciliación entre constituciones formales y materiales". ${ }^{4}$

Algunos de los rasgos de los textos promulgados en esta época que constituyen nuevas tendencias para el área son los siguientes: incorporación de normas-principio; refrendo de vías de participación directa en el poder público; reconocimiento a las minorías étnicas y pueblos originarios, y el compromiso del Estado hacia la protección de su identidad cultural, sus usos y el respeto

\footnotetext{
${ }^{2}$ Empleo el término en un sentido semántico, no en la perspectiva que lo ha utilizado un sector de la academia para denominar a "los procesos jurídicos políticos latinoamericanos surgidos a raíz de movimientos populares consolidados a través de la activación directa y desarrollo democrático de procesos constituyentes". MARTinez DALMAU, RuBĖN, "El proceso constituyente: la activación de la soberanía", en Iñigo ErRéón y Alfredo SerRano (coords.), iAhora es cuándo carajoi Del asalto a la transformación del Estado en Bolivia, España, Ediciones de Intervención Cultural, 2011, p. 37.

Sobre esa visión consultar, entre otros: Viciano Pastor, Roberto y Martinez Dalmau, Rubén, "El nuevo constitucionalismo latinoamericano: fundamentos para una construcción doctrinal", Revista General de Derecho Público Comparado, No. 9, 2011, pp. 1-24. Viciano Pastor, Roberto y Martinez Dalmau, Rubén, "Los procesos constituyentes latinoamericanos y el nuevo paradigma constitucional", Revista IUS, No. 25, México, Instituto de Ciencias Jurídicas de Puebla, 2010, p. 7-29. Viciano Pastor, Roberto, Estudios del nuevo constitucionalismo Latinoamericano, Valencia, Tirant lo Blanch, 2012. Gargarella, Roberto y Courtis, Christian. El nuevo constitucionalismo Latinoamericano: promesas e interrogantes, Santiago de Chile, CEPAL, 2009. Gargarella, Roberto, "El nuevo constitucionalismo latinoamericano. Algunas reflexiones preliminares", Crítica y Emancipación, año 2, No. 3, Buenos Aires, Clacso, 2010, pp. 169-188. Villabella Armengol, Carlos Manuel, Nuevo constitucionalismo Latinoamericano ¿Un nuevo paradigma?, México, Editorial Juan Pablo, 2014.

${ }^{3}$ El vocablo neoconstitucionalismo no tiene una explicitación univoca. Se empleó para significar una multiplicidad de tendencias en el ámbito de la teoría del derecho y el derecho constitucional. Algunos de los ejes doctrinales que subsume son los siguientes: ampliación de los ámbitos de la constitución (diversificación de los objetos), incorporación de normas-principios en el discurso constitucional (principismo), aceptación del trasfondo moral del derecho (axiología), eficacia directa de las normas (materialidad), maximización de los mecanismos de defensa (garantismo), multiplicación y especificidad de los derechos (progresividad de la dignidad humana), interconexión de la constitución con los tratados y convenios de derechos humanos (principio pro-persona), prevalencia de una hermenéutica no gramatical en sede jurisdiccional (regla de ponderación), activismo del juez constitucional (hermenéutica estimativa-manipulativa), hegemonía de la constitución (Estado constitucional). Se ha planteado que con el neoconstitucionalismo advino un "nuevo tipo de derecho que destronó el enfoque paleopositivista" (FERrajol, LuIGI, "Sobre los derechos fundamentales", en Miguel Carbonell (ed.), Teoría del neoconstitucionalismo. Ensayos escogidos, Madrid, Trotta - UnAm, 2007, p. 71) "que surgió una novedosa doctrina constitucional" (Atienza, Manuel, El sentido del derecho, Barcelona, Ariel, 2001, p. 309) y "se engendró una nueva teoría expresiva de perspectivas teóricas, ideológicas y metodológicas renovadoras" (Comanduccl, Paolo, "Formas de (neo)constitucionalismo: un reconocimiento metateórico", Isonomia, No. 16, abril 2002, pp. 89 y ss.). Sobre el neoconstitcionalismo, véase la compilación de trabajos en Carbonel, Miguel, Teoría del Neoconstitucionalismo. Ensayos escogidos, Madrid, Trotta - unam, 2007. Neoconstitucionalismo (s), Madrid, Trotta - unam, 2007.

${ }^{4}$ Viciano Pastor, Roberto y Martinez Dalmau, Rubén, "Los procesos constituyentes latinoamericanos y el nuevo paradigma constitucional", Revista Ius, No. 25, México, Instituto de Ciencias Jurídicas de Puebla, 2010, p. 11.
} 
a sus formas de organización; refrendo amplio de derechos sociales y económicos, a la par de políticas públicas para su implementación; legitimación de derechos colectivos y difusos; afirmación del rango constitucional de los tratados suscritos en materia de derechos humanos.

Estos textos continuaron la transformación del control de constitucionalidad en la región, no sólo porque institucionalizaron cortes constitucionales y salas especializadas, sino porque perfilaron modelos mixtos y duales de justicia constitucional. De igual forma, prosiguió la mutación del presidencialismo: se configuraron varios modelos dentro de este sistema de gobierno. De las cartas magnas de esta época resaltan las de Brasil, Colombia y Ecuador por la magnitud de los cambios.

El texto de Brasil de 1988, redactado por el Congreso Nacional en funciones constituyentes, a tenor de la Enmienda Constitucional 26/1985, incorporó principios y mandatos a los poderes públicos, reguló una amplia relación de derechos, estableció políticas de protección a grupos vulnerables, legitimó mecanismos de participación directa, refrendó diversas vías de garantías a los derechos, reconoció a las minorías indígenas y afrodescendientes, estableció principios para la actividad económica y agraria, y se pronunció por la integración latinoamericana.

La Constitución de Colombia de 1991, que emergió de una asamblea constituyente activada por movilización ciudadana, ${ }^{5}$ refrendó diversos principios que sistematizó en un título; reconoció de manera explícita a las minorías étnicas y culturales; refrendó un amplio cuerpo de derechos sociales y colectivos; declaró la conexión de la dogmática constitucional con los tratados internacionales sobre derechos humanos, estipuló la responsabilidad del Estado en la protección de los grupos vulnerables, incorporó diversos mecanismos de protección a los derechos, estableció la obligación del Estado en la protección de los recursos naturales y la dirección de la economía, legitimó formas de participación ciudadana, y se pronunció por la integración de la comunidad latinoamericana.

La Carta Magna de Ecuador de 1998, redactada por una asamblea constituyente (convocada en 1997 por el gobierno interino de Fabián Alarcón), recogió diversos principios y deberes cívicos en un capítulo inicial; estipuló la eficacia directa de los derechos refrendados en la constitución y los tratados internacionales; institucionalizó diversas formas de participación directa; positivó ampliamente derechos sociales y colectivos, así como programas de

\footnotetext{
${ }^{5}$ En este propósito fue relevante la acción de los estudiantes, quienes propusieron incluir en las votaciones generales de 1990 una séptima papeleta, expresiva de la voluntad de un nuevo pacto constitucional. Véase: CarRiLlo, Fernando, "La quijotada de la séptima papeleta", Revista Cambio, No. 418, 21 de junio 2001. [Consultada 14 de junio de 2012]. Disponible en: https://fundacionseptimapapeleta.wordpress.com/acerca-de/
} 
apoyo para su realización; estableció la protección a los grupos vulnerables; reconoció la existencia de los pueblos indígenas y afroecuatorianos; refrendó vías jurisdiccionales de defensa de la constitución; estableció principios reguladores de la actividad de los partidos políticos; implementó la Comisión de Control Cívico a la corrupción; planteó principios y objetivos rectores de la economía; estipuló un régimen económico sobre la coexistencia del sector público y privado, la función social de la propiedad privada y el dominio estatal sobre los recursos nacionales; enfatizó la jerarquía de la constitución e implementó un tribunal constitucional.

Finalmente, en la primera década del siglo xxi se promulgaron constituciones en Venezuela (1999), Ecuador (2008), y Bolivia (2009). Éstas contornaron un nuevo paradigma que he identificado como novísimo constitucionalismo. ${ }^{6}$ Se destacaron por la manera en que se gestaron en procesos constituyentes originarios, los contenidos novedosos que incorporaron y la manera de regularlos, la innovación en instituciones, el enfoque rupturista con fórmulas del constitucionalismo clásico y el sentido transformador de sus preceptos.

Algunas características de estos textos son los siguientes: alta presencia de principios, valores y mandatos al Estado, los que brindan un plexo axiológico, marcan responsabilidades a los poderes públicos y delinean un rumbo programático; profuso refrendo de derechos y novedosa regulación en cuanto al objeto, contenido y titularidad de algunos de ellos; normativización de derechos novedosos; amplia protección de las minorías étnicas y los grupos originarios, junto al reconocimiento de sus derechos, formas de convivencia y modalidades de autogobierno; empleo de lenguas nativas (aymara, guaraní y quechua); novedosa presentación de los deberes al incorporar obligaciones cívicas; estructuración del poder político público sobre principios organizacionales de nuevo tipo; refrendo de numerosas vías de participación directa que impulsan un empoderamiento ciudadano del poder político; reconocimiento del protagonismo del Estado en el logro de objetivos sociales, a través de los fines, funciones o deberes del Estado; regulación extensa de la constitución económica y del papel del Estado en el manejo de las políticas económicas y financieras; consagración de políticas de integración regional sobre la base de la solidaridad, equidad, igualdad, respeto y complementariedad; regulación de la participación del constituyente originario en el procedimiento de reforma constitucional; y refrendo de órganos de control concentrado y semiespecializado.

\footnotetext{
${ }^{6}$ Véase Villabella Armengol, Carlos Manuel, El Nuevo constitucionalismo Latinoamericano: ¿Un nuevo paradigma?, México, Editorial Juan Pablo, 2014, pp. 73 y ss.
} 
Los aspectos descritos denotan que el constitucionalismo latinoamericano de última data desarrolló las variables del neoconstitucionalismo al desplegarlas con sentido autóctono e incorporar contenidos e instituciones, pero a diferencia de la doctrina europea que constituyó una sistematización ex post facto de rasgos divergentes que evolucionaban desde la segunda postguerra, el novísimo derecho constitucional de la región germinó al margen de doctrinas consolidadas. Su crisol fueron las necesidades sociales y económicas acumuladas, la crisis del sistema político y la necesidad de cambio; de allí el tono emancipador de sus normas y el sentido transformador de su discurso.

De estas constituciones debe ponderarse su vocación transformadora, sus propuestas experimentales y su sentido rupturista con fórmulas del constitucionalismo tradicional. Luego de años de inmovilismo y de calco de tendencias norteamericanas o europeas, trasciende un movimiento como el reseñado de cariz iconoclasta, innovador y procurador de justicia social. Empero, también he señalado que la exuberancia de principios y contenidos de estos textos, la fragilidad de algunas de sus propuestas institucionales, su dependencia de una economía con superávit para hacerse realidad, y su dependencia de un liderazgo de raigambre populista incapaz de reciclarse, son aspectos que atentan contra su reproductibilidad como modelo constitucional.

\section{La Constitución de 1917, documento sui generis}

La Constitución mexicana constituye un documento excepcional en América Latina por su vigencia centenaria en un entorno de fragilidad constitucional. Trasciende también por sus valores históricos; entre ellos, la regulación precursora de derechos laborales (derecho al trabajo, jornada máxima de ocho horas, protección al trabajo femenino y juvenil, derecho al descanso, protección a la maternidad, salario mínimo, salario igual por trabajo igual, protección en caso de accidente de trabajo o enfermedad profesional, derecho a la huelga, indemnización en caso de despido) y la innovación del juicio de amparo como mecanismo de garantía de los derechos.

Resalta, además, junto con su vigencia ininterrumpida, el hecho de que en estos cien años el texto ha tenido 684 enmiendas a través de 227 decretos de reforma, lo cual la convierte en la Carta Magna más reformada del mundo. ${ }^{7}$ No se han modificado los artículos 8 (derecho de petición), 9 (derecho de

\footnotetext{
${ }^{7}$ Las reformas se han clasificado en formales, innovadoras, relacionadas con los poderes públicos, federalizadoras y seguidoras de tendencias. Véase Fix-Zamudio, Héctor y Valencia Carmona, Salvador, Derecho constitucional mexicano y comparado, México, Porrúa, 2001, pp. 119 y ss.
} 
asociación), 12 (prohibición de títulos nobiliarios), 13 (prohibición de leyes privativas de libertad y tribunales especiales), 23 (prohibición de juzgar dos veces por la misma causa), 38 (causales de la suspensión de derechos), 39 (soberanía popular), 47 (extensión del estado de Nayarit), 50 (integración del poder legislativo), 57 (elección de suplente por senador), 64 (suspensión de dieta a los legisladores por inasistencia a sesiones de la cámara), 68 (residencia de las cámaras), 80 (integración del poder ejecutivo), 81 (elección del presidente), 86 (renuncia del presidente), 91 (requisitos para ser secretario de estado), 118 (prohibiciones de las entidades federativas), 126 (principio de legalidad presupuestaria), 128 (protesta de los funcionarios públicos), 129 (límites de la autoridad militar en tiempos de paz), 132 (propiedad de los poderes federales) y el 136 (inviolabilidad de la constitución).

Por el contrario, se corrigieron en más de una docena de ocasiones los siguientes artículos: el 4, en catorce ocasiones (igualdad entre hombre y mujer, derecho a la alimentación, salud, medio ambiente, agua, vivienda, cultura, deporte, e interés superior del menor); el 27, en veinte oportunidades (propiedad de la nación y recursos naturales, propiedad agraria, expropiación); el 73, en setenta y seis momentos (facultades del Congreso); el 74, en diecisiete veces coyunturas (facultades de la Cámara de Diputados); el 76, en quince ocasiones (facultades del Senado); el 79, en quince ocasiones (fiscalización superior de la Federación); el 89 en dieciocho oportunidades (facultades del presiente); el 107, en dieciséis momentos (juicio de amparo); el 115, quince veces (municipios, gobierno local, servicio municipales); el 116, en trece coyunturas (poderes estaduales); el 122, en trece momentos (Distrito Federal); y el 123, en veintiséis ocasiones (derecho al trabajo y otros derechos vinculados).

En todos los sexenios se realizaron enmiendas. Los presidentes más activos fueron: Miguel de la Madrid Hurtado, con 66 artículos reformados, Ernesto Zedillo Ponce de León, con 77 apartados enmendados, Felipe de Jesús Calderón Hinojosa, con 110 preceptos modificados, y Enrique Peña Nieto, con 147 artículos reformados (en esta cuenta se incluyen las disposiciones transitorias y el hecho de que algunos artículo se reformaron en más de una ocasión). ${ }^{8}$

La técnica de reformar la Constitución de manera parcial y reiteradamente ha provocado artículos extensos que yuxtaponen contenidos de manera inorgánica. Verbi gratia, el precepto cuarto refrenda diversos derechos colectivos y difusos junto al derecho individual a la libertad de procreación, el principio de

${ }^{8}$ Centenario Constitución Política de los Estados Unidos Mexicanos, Reformas a la Constitución de 1917, Cámara de Diputados. [Consultado 14 de agosto de 2016]. Disponible en: http://www.diputados.gob.mx/LeyesBiblio/ref/ cpeum_per.htm 
igualdad de sexo, y el principio de interés superior de los niños y las niñas (que por demás se presenta como continuación del derecho de la familia a disfrutar de vivienda). En la misma tesitura puede citarse el artículo 27, el cual regula los bienes propiedad de la nación, la propiedad agraria, las asociaciones religiosas, las sociedades mercantiles, las instituciones de beneficencia, los bancos, los órganos públicos y las representaciones diplomáticas extranjeras. Se incorporó a este precepto el dominio público de los hidrocarburos y la producción de la energía eléctrica y nuclear, el procedimiento de expropiación, la estructura de la justicia agraria y sus principios, y el deber del Estado en la planeación integral y sustentable rural con el fin de producir alimentos.

Ese híper-reformismo denota el fetichismo normativo y formalista que subyace en la sociología jurídica mexicana, que, por demás, no siempre ha sido correspondido con las acciones necesarias para producir la transformación material. Un ejemplo ilustra: el derecho a la educación reglado en el artículo tercero contaba en el documento original con diez líneas que desarrollaban la libertad de enseñanza, el carácter laico de la educación oficial, la prohibición de que las corporaciones religiosas establecieran escuelas, y la gratuidad y supervisión de la enseñanza primaria. En la actualidad, luego de diez reformas y la expansión del artículo a veintisiete párrafos que añadieron diversos aspectos (los objetivos de la educación pública, los criterios educativos, las características de los planes y programas, los fines del Instituto Nacional para la Evaluación Educativa), la enseñanza de calidad sigue siendo una tarea pendiente.

\section{La Carta Magna mexicana a la luz del derecho comparado latinoamericano}

Como se expuso sintéticamente, el derecho constitucional de la región se ha renovado formal y materialmente, generando, en mi opinión, aportes y líneas renovadas de análisis en la teoría constitucional. ¿Se ha desarrollado el constitucionalismo mexicano en la misma dimensión? A continuación realizo un estudio comparado a partir de tres variables trascendentes en el constitucionalismo contemporáneo: la axiología constitucional, el control de constitucionalidad y la forma de gobierno.

\section{a) Variable primera de análisis}

Las normas-principios ponderan valores, establecen deberes cívicos, delinean modelos de comportamiento y delimitan fines teleológicos, lo cual connota moralmente al derecho y éticamente al poder político en una sociedad. En esa 
tesitura, los principios delinean un decálogo para la vida social y política de una comunidad:

El poder y el ordenamiento estatales no valen, no son tales sólo por asumirse y ejercerse el primero conforme a las reglas y los procedimientos constitucionalmente prescritos, por emanar simplemente dicho poder del segundo. Valen porque derivan su validez última de los valores que propugnan y realizan respectivamente, en otras palabras encuentran en dichos valores el parámetro de validez o legitimidad. ${ }^{9}$

$\mathrm{Al}$ refrendarse en la constitución los principios que una sociedad pacta como paradigmas de su existencia, se delinea un techo ideológico que condiciona la actuación de los operadores políticos y jurídicos y la vida social. Ese plexo de valores y principios funcionan como hipótesis metajurídicas que deben optimizarse en el desarrollo legislativo, la conformación y ejecución de las políticas públicas, y la exégesis jurídica, por ello su trascendencia: "Asumido un valor determinado como prominente, como privilegiado [...] se opera la reconstrucción del sistema de modo que todas las demás fórmulas o proposiciones normativas que parecen indicar el surgimiento de valores distintos o contradictorios se consideran genéricamente de grado inferior". ${ }^{10}$

La tendencia de incorporar este tipo de normas en las constituciones evolucionó en el constitucionalismo de postguerra y se convirtió en un rasgo doctrinal del neoconstitucionalismo, conformándose entonces una noción axiológica de constitución diametralmente opuesta a la concepción normativista y aséptica del positivismo jurídico. Bajo ese prisma, la supremacía de la ley de leyes se expresa no sólo formalmente, sino también deontológicamente:

El contenido de la constitución no se agota en el significado de sus términos y enunciados, la naturaleza última de las normas constitucionales es prelingüistica, es axiológica. Por eso las constituciones dicen más de los que los términos significan. Consiguientemente, la indeterminación semántica de las normas constitucionales es compatible con su plena determinación material; son mandatos precisos pese a su imprecisión lingüística. ${ }^{11}$

\footnotetext{
${ }_{9}^{9}$ Parejo Alfonso, Luciano, "Constitución y valores del ordenamiento constitucional y el ordenamiento jurídico", en Compilación de textos para Seminario Internacional, Universidad de Alicante, 1997, p. 104.

${ }^{10}$ Pietro Barcelona, El Estado y los juristas, Barcelona, Fontanella, 1976, p. 67.

1 Bernal Puldoo, Carlos, "Refutación y defensa del neoconstitucionalismo", en Miguel Carbonell (ed.), Teoría del neoconstitucionalismo. Ensayos escogidos, Madrid, Trotta - unam, 2007, p. 239.
} 
Como se expuso, el constitucionalismo latinoamericano de los últimos años incorporó -con prolijidad en algunos casos- este tipo de norma. Exempli gratia, la Constitución de Brasil de 1988 planteó que el Estado debe asegurar el ejercicio de los derechos sociales e individuales, la libertad, la seguridad, el bienestar, el desarrollo, la igualdad y la justicia como valores supremos; construir una sociedad libre, justa y solidaria; garantizar el desarrollo nacional, erradicar la pobreza y la marginación y reducir las desigualdades sociales y regionales; y promover el bien de todos, sin prejuicios de origen, raza, sexo, color, edad o cualquier otra forma de discriminación.

En idéntica tesitura, la Constitución de Colombia de 1991 estipuló que el Estado tiene la obligación de asegurar a sus integrantes la vida, la convivencia, el trabajo, la justicia, la igualdad, el conocimiento, la libertad y la paz; servir a la comunidad; promover la prosperidad general; garantizar la efectividad de los principios, derechos y deberes; facilitar la participación de todos en las decisiones que los afectan y en la vida económica, política, administrativa y cultural de la nación; promover las condiciones para que la igualdad sea real y efectiva; y manejar los recursos naturales para garantizar el desarrollo sostenible del país.

La Constitución de Ecuador de 2008 refrendó disímiles valores, entre ellos: convivencia ciudadana en diversidad y armonía con la naturaleza para alcanzar el buen vivir (sumak kawsay); solidaridad; responsabilidad social y ambiental; sustentabilidad ambiental; justicia social; respeto a las diferentes culturas urbanas; equilibrio entre lo urbano y lo rural; respeto a la diferencia; interculturalidad; no discriminación; transparencia; inclusión; equidad social; aplicación del derecho bajo el criterio pro-persona; promover el bien común y anteponer el interés general al interés particular; transparencia.

En similar sentido se expresó la Constitución de Bolivia de 2009 que contempló como principios ético-morales de la sociedad el ama qhilla, ama llulla, ama suwa (no seas flojo, no seas mentiroso, no seas ladrón), suma qamaña (vivir bien), ñandereko (vida armoniosa), teko kavi (vida buena), ivi maraei (tierra sin mal) y qhapaj ñan (camino o vida noble). Asimismo, estableció que el Estado promueve la unidad, igualdad, inclusión, dignidad, libertad, solidaridad, reciprocidad, respeto, complementariedad, armonía, transparencia, equilibrio, equidad social y de género en la participación, bienestar común, responsabilidad, justicia social, redistribución de los productos y bienes sociales para vivir bien, equidad de género, no violencia, bien común, sustentabilidad, justicia, y transparencia.

La Constitución mexicana de 1917, por la fecha de su concepción, no incluyó este tipo de normas; pero cien años después, y luego de cientos de reformas, sigue 
siendo refractaria a la regulación de principios y valores. El texto menciona la palabra valor en veinte ocasiones; sólo en una de ellas se refiere al valor identidad nacional. Emplea la denominación principio 89 veces, pero en ningún caso en el ámbito de principios éticos o cívicos (la mayoría de ellas para referirse a los principios de constitucionalidad, legalidad, mayoría relativa, proporcionalidad, transparencia, imparcialidad, autonomía, separación de poderes, competencia, autonomía, no discriminación, publicidad o principios generales del derecho). Alude a la dignidad humana únicamente en el artículo primero, luego de la reforma de junio del 2011, para contemplarla como cláusula de no discriminación.

Puede acotarse, no obstante, que en el nuevo paradigma de derechos humanos construido con las reformas constitucionales de los últimos años, se considera como parte de la constitución a los tratados internacionales suscritos por México, con lo cual se incorpora de facto al orden constitucional los principios y valores suscritos por el derecho internacional de los derechos humanos.

Con respecto a la inclusión de principios en la Constitución, hay dos claras posiciones. La postura positivista que rechaza su inserción al considerar que atenta contra el valor normativo de la Carta Magna y trastoca su rol como norma de mínimos; y la concepción deontológica que acepta el trasfondo moral del derecho y el valor sustancial de los principios. En este punto, admito que los ejemplos latinoamericanos citados son casos extremos de principismo constitucional; pero en el reverso, en México observamos a una Constitución sin principios.

\section{b) variable segunda de análisis}

El constitucionalismo latinoamericano ha transitado por diferentes esquemas de control. Primero se asumió el control político que introdujo nominalmente la Constitución de Cádiz de $1812 ;^{12}$ luego se acogió el judicial review, aunque su recepción no constituyó un calco del sistema americano; ${ }^{13}$ posteriormente, se introdujo el modelo europeo. A partir de las últimas décadas del siglo pasado, se configuraron arquetipos orgánicos híbridos que combinaron órganos y

${ }^{12}$ El control político fue adoptado durante la primera mitad del siglo xIx en países como Brasil, Bolivia, Chile, Costa Rica, México y Perú. Estos depositaron la función en una cámara del legislativo o en el Consejo de Estado, órgano de estirpe francesa que fungía como ente consultivo y asesor del ejecutivo, y atendia las infracciones de la constitución. ${ }^{13}$ Una razón es que la función de control se concentró en algunos paises el máximo órgano judicial, privando a los jueces de instancia de la facultad de desaplicar la norma en un caso concreto. Ese monopolio en la revisión de constitucionalidad ha provocado que algunos estudiosos consideren que en realidad se estructuró un tipo de control concentrado en manos de Corte Suprema. Otra novedad fue que se instrumentaron vías procesales directas para demandar la inconstitucionalidad. Ejemplos de ello fueron el amparo creado por la Constitución de Yucatán de 1841 e instituido nacionalmente por el Acta Constitutiva y de Reformas de 1847, y la acción popular instaurada por la Constitución de Cundinamarca de 1811 y la Constitución de Venezuela de 1858. 
procedimientos de los modelos concentrado y americano. Este fenómeno fue consecuencia de la universalización de la justicia constitucional que se produjo con posterioridad a la segunda postguerra y que suscitó el final de la antítesis de los cánones europeo-kelseniano (concentrado, principal, por acción, abstracto, general, constitutivo, a priori y a posteriori, ex nunc y erga omnes) y americano-judicial (difuso, incidental, por excepción, concreto, especial, declarativo, a posteriori, y ex tunc). ${ }^{14}$

El primer órgano de control ad hoc en la región fue instituido por la Constitución de Guatemala de 1965, con la denominación de Corte Constitucional; ${ }^{15}$ En 1971, Chile, a tenor de una reforma, creó el Tribunal Constitucional. En 1979, la Carta Magna de Perú instituyó el Tribunal de Garantías Constitucionales, luego denominado Tribunal Constitucional. En 1991, se originó la Corte Constitucional de Colombia con la Constitución de igual fecha. En 1994 nació el Tribunal Constitucional de Bolivia mediante una reforma constitucional, órgano que posteriormente se nombró Tribunal Constitucional Plurinacional en la Ley de Leyes de 2009.

El primer canon de control constitucional desempeñado por una sala del máximo órgano judicial fue el Tribunal de Garantías Constitucionales y Sociales implementado por la Constitución cubana de 1940. La Constitución de Ecuador de 1945 creó igualmente un Tribunal de Garantías Constitucionales, aunque más limitado en sus funciones que el anterior. Éste posteriormente se remodeló como Tribunal Constitucional en la Constitución de 1998, y la Constitución de 2008 lo refrendó como Corte Constitucional.

Este formato de salas constitucionales en la máxima magistratura fue seguido, décadas más tarde, por varios países. En 1983, El Salvador la implementó en la Constitución de ese año. En 1989, Costa Rica la adoptó con la enmienda al texto de 1949. En 1992, Paraguay la acogió en la Constitución de igual fecha. En 1995, Nicaragua la introdujo mediante una reforma a la Constitución de 1987. En 1999, Venezuela la instituyó a través de la Carta Magna. En el 2000, Honduras la instauró mediante una reforma a la Constitución de 1982. En la actualidad, doce países han adoptado órganos especializados o semiespecializados de control constitucional, los cuales en muchos casos se articulan en su función con instancias del poder judicial. Así, se ha configurado en la región un arco variopinto de modelos en los cuales se yuxtaponen rasgos y órganos.

\footnotetext{
${ }^{14}$ Véase Fernández Segado, Francisco, "La justicia constitucional ante el siglo xxl: la progresiva convergencia de los sistemas americano y europeo-kelseniano", Revista Pensamiento Constitucional, vol. 11, No. 11, Pontificia Universidad Católica de Perú, 2005, pp. 20-75.

${ }^{15}$ El tribunal no constituyó inicialmente un órgano permanente. Existió hasta 1982, cuando se produjo un golpe de Estado y se retomó en la Constitución de 1985.
} 
Exempli gratia, el modelo de control constitucional de Colombia es exponente de hibridación de rasgos e instancias. La Corte Constitucional insertada en el poder judicial tiene la función de guardar la integridad y supremacía de la Constitución, según reza el artículo 241 de la Constitución de 1991. En ese plano, soluciona las demandas de inconstitucionalidad presentadas por los ciudadanos contra leyes y decretos con fuerza de ley dictados por el gobierno; decide sobre la exequibilidad de los tratados internacionales; atiende las revisiones de la constitucionalidad de las reformas de la Constitución; ejercer control previo en los proyectos de ley que hayan sido objetados por el Gobierno como inconstitucionales; y se pronuncia preventivamente sobre la constitucionalidad de la convocatoria a referendo, asamblea constituyente, consultas populares y plebiscitos. Revisa además discrecionalmente, o a solicitud del defensor del pueblo, las decisiones judiciales relacionadas con la acción de tutela de los derechos constitucionales.

Por su parte, todos los jueces tienen atribución para conocer de la acción de tutela de derechos fundamentales mediante un procedimiento preferente y sumario, y resuelven la acción de cumplimiento que presenten los ciudadanos para hacer efectiva la observancia de una ley o un acto administrativo. Los tribunales administrativos conocen además de las acciones de nulidad por inconstitucionalidad de actos administrativos de carácter general, impersonal y abstracto. Asimismo, la jurisdicción de lo contencioso administrativo y la jurisdicción ordinaria civil, dirimen las acciones colectivas para la protección de los derechos e intereses colectivos, y las acciones de grupo que se susciten para el reconocimiento y pago de indemnización de perjuicios.

Al diagrama orgánico anterior, hay que agregar al Consejo de Estado, tribunal supremo de lo contencioso administrativo y cuerpo consultivo del gobierno en asuntos de administración, que tiene entre sus funciones conocer de las acciones de nulidad por inconstitucionalidad de los decretos dictados por el gobierno y cuya competencia no corresponda a la Corte Constitucional.

Por su parte, el sistema de control constitucional de Ecuador es ejemplo de mecanismo dual al coexistir el control abstracto para asegurar la unidad y coherencia del ordenamiento en manos de la Corte Constitucional, y el control concreto para garantizar la constitucionalidad de la aplicación de las disposiciones jurídicas dentro de los procesos judiciales.

La Corte Constitucional es un órgano autónomo que, según lo define el artículo 429 de la Constitución de 2008, es la máxima instancia de control, interpretación constitucional y justicia en esta materia. En ese sentido, tiene amplias atribuciones, entre ellas: conoce la acción pública de inconstitucionalidad contra actos normativos; declara de oficio la inconstitucionalidad de 
normas conexas en los casos que ventila; resuelve la acción de incumplimiento de normas o actos administrativos y de sentencias o informes de organismos relacionados con derechos humanos; atiende las acciones de inconstitucionalidad contra reformas de la constitución, resoluciones aprobatorias de tratados internacionales y leyes de urgencia económica; y declara la inconstitucionalidad por omisión de mandatos constitucionales. También dirime conflictos de competencia entre órganos del Estado y ejerce control previo sobre la constitucionalidad de los tratados internacionales, la convocatoria a referendo, consulta popular e iniciativa popular normativa.

Paralelamente, los jueces de instancia son competentes para conocer las garantías jurisdiccionales (acción de protección, hábeas corpus, acción de acceso a la información pública, hábeas data, acción por incumplimiento, acción extraordinaria de protección y acción extraordinaria de protección contra decisiones de la justicia indígena). Asimismo, en caso de que una norma que deba aplicar sea contraria a la Constitución o a los tratados de derechos humanos, puede suspender la tramitación de la causa y consultar a la Corte Constitucional.

La Corte Constitucional puede también, discrecionalmente, revisar las sentencias ejecutoriadas de garantías jurisdiccionales dictadas por el juez de instancia, atendiendo a la gravedad, novedad, o trascendencia del caso, o que implique un cambio jurisprudencia.

En el control de constitucionalidad de la región hay que significar, asimismo, la maximización de las garantías de la libertad que se ha producido a partir del refrendo de numerosas vías procesales: acción de amparo, acción de protección, hábeas corpus, acción de acceso a la información pública, hábeas data, acción por incumplimiento, acción extraordinaria de protección, acción extraordinaria de protección contra decisiones de la justicia indígena, mandato de segurança individual y colectivo, mandado de injunção, acción popular. Estas acciones o procesos se imbrican con la jurisdicción trasnacional de la Corte Interamericana de Derechos Humanos. Cappelleti identificó este fenómeno como trasnacionalización de la justicia constitucional; ${ }^{16}$ Alcalá-Zamora, como el derecho procesal constitucional internacional, ${ }^{17}$ y Prieto-Sanchís como un constitucionalismo internacional basado en los derechos humanos. ${ }^{18}$

\footnotetext{
${ }^{16}$ Cappellettl, Mauro, "Justicia Constitucional supranacional. El control judicial de las leyes y la jurisdicción de las libertades a nivel internacional", Revista de la Facultad de Derecho de México, México, No. 110, mayo-agosto 1978, pp. 237 y ss. [Consultado 21 de febrero de 2016]. Disponible en: http://www.juridicas.unam.mx/publica/rev/indice. $\mathrm{htm} ? \mathrm{r}=$ facdermxtn $=110$

${ }^{17}$ Alcalá-Zamora, Niceto, La protección procesal internacional de los derechos humanos, Madrid, Civitas, 1975, pp. 49 y ss.

${ }^{18}$ Prieto-Sanchis, Luis, Justicia constitucional y derechos fundamentales, Madrid, Trotta, 2013, pp. 235 y sS.
} 
En México, algunos autores señalan que la reforma constitucional de agosto de 1987 fue el primer paso en la conversión de la Suprema Corte en órgano de control constitucionalidad, ${ }^{19}$ aunque realmente el momento determinante lo constituyó la reforma de diciembre de 1994. Esta enmienda estructuró de una manera más reducida y calificada al máximo órgano judicial; creó el Consejo de la Judicatura como ente responsable del gobierno y la administración del poder judicial, deslastrando a la Suprema Corte de este quehacer; y concentró en ella la jurisdicción constitucional. Amplió además el rango de las controversias constitucionales y creó la acción de constitucionalidad, reforzándose así el control abstracto y orgánico de la Constitución.

Un siguiente momento fue la promulgación de la Ley de Amparo en abril del 2013, luego de dieciséis años de haberse presentado el proyecto en comisiones legislativas, y setenta y siete años sin adecuarse la institución de amparo (la ley anterior databa de 1936). La nueva ley introdujo novedades que reforzaron este instrumento procesal: amplió el ámbito de protección al incluir a todos los derechos humanos contenidos en la Constitución y los tratados internacionales; ensanchó la procedencia al contemplar que la acción lesiva puede provenir de normas, actos y omisiones, que vulneren derechos subjetivos o afecten el interés legitimo; dilató el concepto de autoridad al incluir a los particulares cuando realicen actos de esta envergadura y vulneren derechos; refrendó que la sentencia de amparo directo tendría efectos erga omnes (declaratoria de inconstitucionalidad) cuando hubiese dos fallos reiterativos y en acciones y controversias constitucionales cuando la sentencia fuera aprobada por mayoría de ocho votos; incluyó el amparo colectivo; e introdujo cambios procedimentales que posibilitan concentrar acciones y abreviar la controversia.

Por último, el 29 de enero de 2016 se reformaron varios artículos constitucionales, entre ellos del 101 al 107, referidos al poder judicial y sus funciones de jurisdicción constitucional. ${ }^{20}$ Como puede observarse, las trasformaciones en el control de constitucionalidad en México has sido tardías y limitadas en relación con otros países de la región, ${ }^{21} \mathrm{y}$ en ningún caso han contemplado

${ }^{19}$ CARPIZ, Jorge, "Reformas constitucionales al poder judicial y a la jurisdicción constitucional, del 31 de diciembre de 1994", Boletín Mexicano de Derecho Comparado, No. 83, mayo-agosto 1995, año 18. [Consultado 12 de enero de 2016]. Disponible en: http://www.juridicas.unam.mx/publica/rev/boletin/cont/83/el/el14.htm

${ }^{20}$ Sobre la remodelación del control de constitucionalidad en México véase Cossio Diaz, José Ramón, Sistemas y modelos de control de constitucionalidad en México, México, unAm, 2013.

${ }^{21}$ Las reformas constitucionales aludidas y la promulgación de la nueva Ley de Amparo, hay que insertarlos en un iter de acciones que produjeron un cambio de paradigma respecto a los derechos humanos, y que renovaron el modelo de control de constitucionalidad. Además de las reformas constitucionales citadas, hay que añadir como momentos importantes los siguientes: la Sentencia de la Corte Interamericana "Radilla Pacheco vs México" de 23 de noviembre de 2009, la cual además de condenar al Estado mexicano obligó al poder judicial a replantear su papel en la defensa de los derechos humanos y en la ejecución de las sentencias del órgano jurisdiccional supranacional. 
el introducir un órgano extra poder (tribunal constitucional) o crear una sala especializada en la máxima magistratura. Ambas ideas son contrarias a la percepción tripartita del poder y la concepción doctrinal prevalecientemente en México. Así, el modelo de control de constitucionalidad existente es concomitante con la idea de Estado de derecho más que con la noción de Estado constitucional.

\section{c) Variable tercera de análisis}

El presidencialismo se diseñó en la Constitución norteamericana de 1787. El arquetipo que se construyó en ese país se caracterizó por los siguientes rasgos esenciales: ejecutivo unicéfalo, el presidente es jefe de Estado y de gobierno; éste es elegido por un colegio de compromisarios que representan el voto de los electores en cada estado; no existe un órgano de gobierno; el titular del ejecutivo es asistido por secretarios para el ejercicio de las funciones de gobierno y administración; el legislativo es bicameral y elegido de manera directa; este órgano no cuenta con mecanismos de control político que provoquen la renuncia de los secretarios; el presidente sólo puede ser forzado a dimitir mediante impeachment; el jefe de Estado no puede disolver al legislativo bajo ninguna circunstancia.

En América Latina todos los países acogieron este sistema de gobierno desde su independencia, con excepción de la experiencia monárquica de México en 1821 y luego entre 1865 y 1867; de Brasil entre 1883 y 1889; y la implementación del modelo de gobierno convencional en Uruguay de 1917 a 1933 y de 1951 a 1966. ${ }^{22}$ Su recepción y predominio en la región se ha explicado con argumentos históricos, culturales y de gobernabilidad, pero la razón fundamental fue el influjo de la Constitución de Estados Unidos. No obstante, su refrendo no fue un clon del prototipo norteamericano ni su funcionamiento ha gozado de la misma estabilidad. Ejemplo de lo primero es la regulación

Derivado de ésta, la Suprema Corte abrió el Expediente "Varios 912/2010" que se resolvió en julio del 2011, donde dilucida, entre otras cosas, la interconexión de la Constitución con los instrumentos de derecho internacional de los derechos humanos, se pronuncia por la obligación de los jueces de realizar ex officio control de convencionalidad, y dejó sin efecto la jurisprudencia 74/1999 que estipulaba que el juez a quo no tenía autoridad para ejercer control de constitucionalidad. Al paralelo, se efectuó la reforma constitucional de junio de 2011 que enmendó once artículos y el título del capitulo primero del texto ("De los Derechos Humanos y sus Garantías"), sustituyéndose la obsoleta denominación de garantías individuales. De los preceptos modificados, resalta la sustancial reforma del artículo primero que creó un nuevo marco regulatorio e interpretativo de los derechos humanos.

${ }^{22}$ La Constitución de 1918 introdujo un modelo de gobierno colegiado, conformado por el presidente electo por cuatro años y el Consejo Nacional de Administración de nueve miembros elegido de forma directa por seis años. La Carta Magna de 1952 eliminó la figura del presidente, desempeñando el Consejo Nacional de Administración la función ejecutiva y de gobierno, éste órgano elegía entre sus miembros cada año a un presidente, que fungía como jefe de Estado. Véase Gross Espiell, Héctor, Las Constituciones del Uruguay, Madrid, Centro de Estudios Constitucionales, 1978. 
más detallada del funcionamiento y facultades del ejecutivo y el legislativo; la elección directa del presidente; su mayor incidencia en el proceso legislativo; la ausencia de vicepresidente en algunos países o la existencia de dos en otras naciones. Expresión de lo segundo es la fragilidad institucional que ha mostrado el presidencialismo en la región, la dificultad para generar democracias estables, y su ejercicio caudillista, clientelar y populista.

La re-democratización ocurrida durante las últimas décadas del siglo anterior en América Latina impulsó la revisión crítica del diseño orgánico-funcional del sistema. ${ }^{23}$ Las acciones de reforma emprendidas conllevaron a su metamorfosis en dos ángulos fundamentales: la delineación de un ejecutivo menos hegemónico y la introducción de instituciones parlamentarias. En esa tesitura, las transformaciones fueron de una soft dimension (conversión nominal de los secretarios en ministros, afirmación de que el presidente y los ministros desempeñan el poder ejecutivo) a una strong dimension (introducción de órganos de gobierno, refrendo del mecanismo de censura a los ministros).

Aunque las reformas comenzaron en las constituciones redactadas en los años sesenta del siglo anterior, los diferentes momentos constitucionales descritos en los primeros epígrafes implicaron momentos de profundización en la mutación del sistema.

\footnotetext{
${ }^{23}$ En el entorno de la recuperación democrática e institucional de la región prosperó el debate sobre el funcionamiento de la forma de gobierno presidencial y su relación con la democracia y la estabilidad política. Un punto de partida del análisis lo constituyó el evento sobre reforma política y estabilidad democrática desarrollado en marzo de 1987 en Fortín de Santa Rosa, Uruguay. A partir de ese momento, el tema se convirtió en centro del debate teórico durante los años noventa, y aún hoy es recurrente en los estudios constitucionales y politológicos. Un sector de los análisis liderados por Juan Linz apostilló que el presidencialismo era un modelo de gobierno tendente, por su estructura orgánica rígida, a la ingobernabilidad, los bajos rendimientos democráticos y la parálisis funcional, propiciando que las crisis de gobernabilidad tiendan a desembocar en crisis del sistema politico (Godor, Oscar, Hacia una democracia moderna. La opción parlamentaria, Santiago, Universidad Católica de Chile, 1990). Otro sector de la academia encabezado por Dieter Nohlen fue más comedido. Razonó que no existen tipologias ideales de formas de gobierno y que el análisis dicotómico presidencialismo vs parlamentarismo basado en el diagrama institucional es engañoso porque desconoce el medio ambiente social, cultural, económico y político en que se desempeña el sistema de gobierno, lo que constituye un factor determinante de su funcionalidad (NoHLEN, DIETER, "Parlamentarismo vs presidencialismo en América Latina. Dos enfoques contrapuestos", en Dieter Nohlen y Mario Fernández Baeza (eds.), El presidencialismo renovado: Instituciones y cambio politico en América Latina, Caracas, Nueva Sociedad, 1998). Sobre las líneas maestras del debate se delinearon como propuestas fundamentales de solución para la región las siguientes: adoptar la forma de gobierno parlamentaria (LINZ, JUAN, "Democracia: presidencialismo o parlamentarismo: ¿Hace alguna diferencia?", en Oscar Godoy (Ed), Hacia una democracia moderna. La opción parlamentaria, Santiago, Universidad Católica de Chile, 1990, pp. 60 y ss.), introducir elementos de éste sistema (Nohlen, Dieter, Sistemas de Gobierno: perspectivas conceptuales y comparativas, en Dieter Nohlen y Mario Fernández Baeza (eds.), Presidencialismo versus Parlamentarismo. América Latina, Carcas, Nueva Sociedad, 1991, pp. 20 y ss.), mutar a un régimen semipresidencial (Nogueira Alcalá, Humberto, "Consideraciones sobre los tipos de gobierno presidencialista y semipresidencialista en la reforma constitucional", Boletín Mexicano de Derecho Comparado, Número conmemorativo, sexagésimo aniversario, 1948-2008, mayo-agosto 2016, Universidad Nacional Autónoma de México, pp. 758 y ss.), o diseñar un presidencialismo alternativo semiparlamentarismo (GIOVANNI, SARToRI, Ingeniería Constitucional Comparada, México, Fondo de Cultura Económica, 1996, p. 168).
} 
La gradación del presidencialismo regional fue advertida por estudiosos del derecho comparado, aunque algunas de las catalogaciones han perdido vigencia porque se realizaron en la época de los gobiernos autoritarios o cuando existía el régimen convencional en Uruguay. Verbigratia, Sánchez Agesta ${ }^{24}$ distinguió entre presidencialismo puro, atenuado, con aproximación al parlamentarismo, y gobierno colegial de Uruguay. Colomer Vida ${ }^{25}$ diferenció entre dictaduras oligárquicas, dictaduras militares, regímenes populistas y regímenes democráticos; y en este último estableció el presidencialismo hegemónico de excepción, el hegemónico constitucional democrático, con sujeción parlamentaria y autónomo de equilibrio de poderes. Loewenstein ${ }^{26}$ destacó al presidencialismo puro, atenuado y de aproximación al parlamentarismo. Bidart $\operatorname{Campos}^{27}$ apreció al presidencialismo puro, híbrido e intermedio. Biscarretti di Ruffia ${ }^{28}$ clasificó al presidencialismo en democrático y autoritario. Nogueira Alcalá consideró al presidencialismo puro, atenuado y parlamentarizado. ${ }^{29}$ Carpizo identificó entre presidencialismo puro, predominante, atemperado, con matices parlamentarios y parlamentarizado. ${ }^{30}$

Siguiendo esta línea de pensamiento, pero simplificando las categorías, distingo en el mapa constitucional actual de Latinoamérica tres tipologías de presidencialismo: puro, atenuado y con correctivos parlamentarios.

El modelo puro tiene una fisonomía cercana al arquetipo norteamericano, y está presente en Chile y México. Debe anotarse como diferencia, que la Constitución chilena dedica una sección a los ministros de estado, lo que otorga un mayor realce a estos funcionarios, aunque el texto precisa que son colaboradores directos e inmediatos del presidente en el gobierno y la administración del Estado.

El modelo atenuado se caracteriza por la despersonalización del poder ejecutivo y la existencia de un órgano de gobierno, aspectos que transmutan el

\footnotetext{
${ }^{24}$ SÁnchez Agesta, LuIS, Curso de derecho constitucional comparado, Madrid, Universidad Complutense de Madrid, 1980 , pp. 245 y 246

${ }^{25}$ Colomer VIDAL, Antonio, "El presidencialismo iberoamericano", en Memorias del IV Congreso Iberoamericano de Derecho Constitucional, México, Universidad Autónoma de México, 1992, pp. 139 y ss.

${ }^{26}$ Loewenstein, KarL, Teoría de la Constitución, Barcelona, Ariel, 1998, pp. 42 y sS.

${ }^{27}$ Bidart Campos, Germán, El constitucionalismo en las postrimerías del siglo xx, México, Universidad Autónoma de México, 1988, pp. 54 y ss.

${ }^{28}$ Biscarettidi Ruffia, Paolo, Introducción al derecho constitucional comparado. Las formas de Estado y las formas de Gobierno. Las Constituciones modernas. 1988-1990: un periodo de profundas transformaciones constitucionales en Occidente, en la unss y en los Estados socialistas del Este europeo, México, Fondo de Cultura Económica, 2000, pp. 190 y ss.

${ }^{29}$ Nogueira Alcalá, Humberto, "Consideraciones sobre los tipos de gobierno presidencialista y semipresidencialista en la reforma constitucional", Boletín Mexicano de Derecho Comparado, Número conmemorativo, sexagésimo aniversario, 1948-2008, mayo-agosto 2016, México, Universidad Nacional Autónoma de México, pp. 711 y ss.

${ }^{30}$ Carpizo, Jorge, Concepto de democracia y sistema de gobierno en América Latina, México, Universidad Autónoma de México, 2007, pp. 179 y ss.
} 
esquema organizacional del sistema. Se ha contornado en Brasil, Costa Rica, El Salvador, Honduras y Nicaragua:

- En Costa Rica, El Salvador, Honduras, y Nicaragua se institucionalizaron consejos de ministros encabezados por el presidente (Costa Rica lo denomina consejo de gobierno). Las constituciones de los primeros dos países le reconocen funciones al órgano y le dedican varios artículos a su regulación.

- Las constituciones de Brasil, Costa Rica y El Salvador exponen que el presidente y los ministros desempeñan el poder ejecutivo como colaboradores; o como señala el texto salvadoreño: un órgano ejecutivo integrado por el presidente, el vicepresidente, los ministros y los vice ministros.

- En todos los países señalados se reconoce la facultad del legislativo de solicitar informes a los ministros e interpelarlos. La Constitución de Brasil plantea que el congreso fiscaliza los actos del ejecutivo, y la de El Salvador que puede recomendar al presidente la destitución de algún ministro.

El modelo de presidencialismo con correctivos parlamentarios se tipifica por la legitimación de instituciones de gobierno y de mecanismos funcionales del sistema parlamentario, aunque no hay rasgos homogéneos en los países que catalogamos de esta forma. Se ha configurado en Argentina, Bolivia, Colombia, Ecuador, Guatemala, Panamá, Paraguay, Perú, Uruguay y Venezuela:

- En Bolivia, Guatemala, y Panamá, el poder ejecutivo se deposita en un órgano integrado por el presidente, el vicepresidente y los ministros. Las constituciones de Ecuador y Venezuela señalan que el presidente es jefe de Estado y de gobierno, pero a la vez se expresa que éste ejerce la función ejecutiva junto a los ministros y funcionarios.

- En todos los países de este grupo, menos en Ecuador, se institucionalizó un órgano de gobierno denominado gabinete de ministros en Argentina, consejo de gabinete en Panamá, gobierno nacional en Colombia y consejo de ministros en los demás.

- Se regulan atribuciones del órgano de gobierno. En el texto de Argentina se refrendan sólo las funciones del jefe de gabinete, en Bolivia las atribuciones de los ministros, y en Venezuela se precisan las facultades que el presidente debe ejercer en compañía del consejo de ministros. Resalta la Constitución de Uruguay que no reconoce atribuciones al presidente de manera unipersonal sino junto a los ministros. 
- Las constituciones refrendan el voto de censura o procedimiento de confianza contra los ministros, procedimiento que de prosperar obliga al ministro a dimitir. En Uruguay la censura puede ser individual, plural contra varios ministros, y colectiva contra el consejo de ministros en pleno. En Venezuela la censura procede también contra el vicepresidente.

- En Argentina y Perú se legitimó un primer ministro que coordina la actividad administrativa, dirige el funcionamiento del consejo y representan al gobierno ante el órgano legislativo. El jefe de gabinete argentino tiene responsabilidad política directa ante el legislativo, y el presidente del consejo de ministros peruano tiene que presentar al congreso el programa político y solicitar su confianza.

- En Perú y Uruguay, se reconoce la cuestión de confianza, mecanismo por el cual el gobierno solicita al legislativo una votación que exponga el respaldo que tiene para instrumentar determinada política.

- Los textos constitucionales de Ecuador, Perú, Uruguay y Venezuela, legitiman que el presidente puede disolver al legislativo en determinados supuestos.

He catalogado la forma de gobierno en México como pura por su apego orgánico y funcional al diseño original de la forma de gobierno presidencial. En ese sentido, el debate parlamentarismo vs. presidencialismo, de gran repercusión en América Latina y que inspiró las transformaciones descritas, no ha tenido resonancia política ni académica en el país.

La idea de rediseñar el sistema de gobierno en México tuvo algún realce a partir del año 2000, en que se produjo la alternancia política con el triunfo en la presidencia de la república del Partido Acción Nacional. Una de las últimas propuestas de reforma estatal trabajada en comisiones de la LXI Legislatura contempló los siguientes aspectos: control político del legislativo a los funcionarios del Estado, el gobierno y la administración; aprobación del Plan Nacional de Desarrollo y el presupuesto de la federación por ambas cámaras; control sobre informe presidencial; responsabilidad política del presidente y de los altos mandos del poder ejecutivo; posibilidad de sustitución del presidente; limitación del fuero constitucional; revocación de mandato; legitimación de referéndum constitucional obligatorio y potestativo; adopción de un Consejo de Estado. ${ }^{31}$

\footnotetext{
${ }^{31}$ Comisiones Legislativas, LXI Legislatura, Congreso de la República, Reforma de Estado, consultado 10 de noviembre de 2015. Disponible en: http://www.senado.gob.mx/comisiones/LX_Legislatura/reformadelestado/_
} 
Si analizamos los capítulos 2 y 3 de la Constitución, que establecen los poderes ejecutivo y legislativo, y constituyen la normatividad básica de la forma de gobierno, comprobamos que los artículos 50 y 80, que describen los poderes legislativo y ejecutivo, no se han sido reformados. A contrario sensu, el resto del articulado de estos acápites se ha modificado en 238 ocasiones (35\% de las enmiendas constitucionales). Esto evidencia que algunos de los preceptos de esos capítulos se encuentran entre los más modificados: el artículo 73 con setenta y siete enmiendas (regula las facultades del Congreso), el artículo 74 con diecisiete cambios (refrenda las atribuciones de la Cámara de Diputados), el artículo 76 con quince correcciones (establece las facultades del Senado), el artículo 79 con quince renovaciones (estatuye la entidad de fiscalización de la federación), y el artículo 89 con dieciocho innovaciones (regla las funciones del presidente).

Respecto a las facultades de las cámaras, las reformas efectuadas introdujeron algunas atribuciones que marcan cierta ascendencia sobre la función ejecutiva. En la Cámara de Diputados: ratificar el nombramiento del secretario de hacienda, revisar la cuenta pública y aprobar el plan nacional de desarrollo. En el Senado: aprobar los tratados internacionales que suscribe el presidente, ratificar el nombramiento de los secretarios de Estado, designar a los ministros de la Suprema Corte y autorizar la estrategia nacional de seguridad.

Merece mencionarse también la institucionalización en 1999 del ente superior de fiscalización con potestad para controlar los ingresos, egresos, manejo, custodia y aplicación de los fondos y recursos del Estado en manos de los diferentes órganos federales y estaduales. Deben comentarse, asimismo, los cambios en el artículo 69 referidos al informe del presidente y el artículo 71 relacionado con la iniciativa y formación de las leyes.

El artículo 69 señalaba en el texto original que, "a la apertura de sesiones ordinarias del primer período del Congreso asistirá el Presidente de la República y presentará un informe por escrito en el que manifieste el estado general que guarda la administración pública del país". ${ }^{32}$ En la reforma del 2008 desapareció la frase asistirá el presidente; quedó sólo la obligación de entregar el informe, y se añadió un segundo párrafo que planteó que cada cámara analizaría el informe y podría solicitar al presidente ampliar la información mediante pregunta por escrito y citar a los secretarios de Estado.

El artículo 71 establecía en el texto primigenio que la iniciativa de las leyes correspondía al presidente, los diputados, senadores y las legislaturas

\footnotetext{
${ }^{32}$ Constitución política de los Estados Unidos mexicanos. [Consultado 12 de agosto de 2016]. Disponible en: http:// www.diputados.gob.mx/LeyesBiblio/ref/dof/CPEUM_ref_107_07abr86_ima.pdf
} 
de los estados. La reforma del 2008 reconoció iniciativa a los ciudadanos y agregó un párrafo en el que señala que al inicio de cada período ordinario el presidente podría presentar hasta dos proyectos para que fueran tramitados con carácter preferente.

A tenor de las reformas descritas, Carpizo consideró que se había producido la parlamentarización del sistema de gobierno. ${ }^{33}$ Por su parte, Fix-Zamudio y Valencia Carmina aseguraron que se ha transitado de un "régimen presidencialista a uno simplemente presidencial", debido a que existen "varios signos que anuncian un esquema diverso en la organización y funcionamiento del ejecutivo". ${ }^{34}$ Acotan que no es recomendable ni necesario efectuar cambios más allá de lo realizado. ${ }^{35}$

Por el contrario, Jaime Cárdenas y otros académicos han sostenido que el ajuste del modelo de gobierno está aún pendiente, y esbozan las siguientes directrices: introducir un primer ministro o figura análoga que coordine la acción de gobierno, intensificar los controles políticos al ejecutivo (aprobación de nombramientos y miembros del gabinete, censura a los secretarios), permitir la reelección del presidente, concederle facultad al ejecutivo de disolver al legislativo en determinados supuestos. ${ }^{36}$

En mi opinión, la cantidad de reformas no ha afectado la cualidad del sistema. El presidente no ha visto disminuida su hegemonía como jefe de Estado y gobierno, cuenta con imperium metaconstitucional que ejerce en el funcionamiento del aparato público y en la vida interna de su partido político. Contrario sensu, no existen mecanismos de control político efectivo que puedan ejercerse sobre la función de gobierno o el jefe de Estado: el presidente constituye un César sexenal inamovible, aunque su descredito sea ostensible. La remodelación que ha existido en la dinámica del sistema de gobierno tiene que ver con la pérdida de predominio político del Partido Revolucionario Institucional, la alternancia política que se ha producido en la presidencia de la república, el surgimiento de nuevas fuerzas políticas, y el cambio de escenario en el Congreso.

Así, resulta fatuo hablar de parlamentarización y es vacuo el juego de palabras de que el presidencialismo se transformó en sistema presidencial. Ese estatismo tiene su explicación inmediata en el hecho de que el sistema político

\footnotetext{
${ }^{33}$ Carpizo, Jorge, El presidencialismo mexicano, México, Siglo XXI, 2002, pp. 31 y ss.

${ }^{34}$ Fix-Zamudio Héctor y Valencia Carmona, Salvador, Derecho constitucional mexicano y comparado, México, Porrúa, 2001, pp. 835 y ss. En un sentido similar, véase ValadÉs, Diego, El control del poder en México, México, unam, 1988, p. 409.

35 Fix-Zamudio Héctor y Valencia Carmona, Salvador, Derecho Constitucional mexicano y comparado, México, Editorial Porrúa, 2001, pp. 835 y ss. En un sentido similar Valadés, Diego, El control del poder en México, México, unAm, 1988, p. 839 .

${ }^{36}$ Cárdenas Gracia, Jalme, Transición política y reforma constitucional en México, México, unam, 1994, pp. 170 y sS.
} 
mexicano ha gozado de estabilidad institucional y continuidad electoral, pero en ello influye también el conservadurismo intelectual y político que bloquea la idea de renovar el sistema de gobierno. Las siguientes palabras pueden servir de ejemplo:

Un análisis serio, profundo y sistemático revela que dichas propuestas de reforma -en realidad una contrareforma nociva para los mejores intereses de la República- constituyen un "espejismo" altamente peligroso pues implican nada menos que el desmantelamiento total de la "coraza" o "blindaje" constitucional que brindan al Estado mexicano [...] el original sistema presidencial plasmado en 1917 [...] deben evitarse en los procesos de reingeniería constitucional [...] los procesos de extrapolación e imitación artificial de instituciones extranjeras. ${ }^{37}$

\section{Epílogo}

El análisis evidencia que la Constitución mexicana quedó a la zaga del constitucionalismo latinoamericano; al menos, su desarrollo no siguió las tendencias que marcaron la evolución del derecho constitucional de la región. En ese punto, el observador foráneo se cuestiona por qué luego de las cientos de reformas que han transfigurado el texto original de 1917, no ha calado la idea de redactar una nueva constitución que exprese la renovación del pacto constituyente, sistematice los cambios efectuados y actualice el contenido constitucional.

La pregunta puede responderse a priori, señalando que el hecho de que no hayan existido interrupciones en la vida política e institucional del país ha posibilitado que la Constitución perdure y que no perciba la necesidad de una reforma total. No obstante, a este argumento deben añadirse dos razones que a mi juicio ejercen una gran influencia en lo que se comenta: una es cultural y la otra de pertinencia política.

Respecto a la primera, basta reproducir las siguientes palabras que traslucen el peso monumental que tiene la Constitución de 1917 en la sociología jurídica y el imaginario nacional:

\footnotetext{
${ }_{37}$ Andrea Sánchez, Francisco José de, "La restauración de los tres pilares del constitucionalismo mexicano: el original sistema presidencial, el principio de no-reelección y el articulado de contenido social", Boletín Mexicano de Derecho Comparado, vol.1, Número Conmemorativo, sexagésimo aniversario, México, Instituto de Investigaciones Jurídicas, 2008, pp. 1-13.
} 
Su carga histórica es tan grande que en la Constitución los mexicanos recrean la herencia ideológica de nuestros sacudimientos sociales, los avances que logró el movimiento revolucionario de este siglo y los principios que rigen a la sociedad civil del presente. A diferencia de otros países, en el nuestro la Constitución ha sido símbolo de estabilidad política y de unidad nacional, en torno a la cual partidos, grupos políticos, y los propios ciudadanos, han desenvuelto las actividades que les son propias. Sentimiento constitucional tan acendrado es difícil de cultivar en los pueblos, por eso hay que mantenerlo y acrecentarlo, tanto porque enraíza en la historia viva, como por su influencia determinante para nuestro destino común. ${ }^{38}$

En cuanto a la segunda, se ha reiterado que una nueva Carta Magna rompería con una historia y tradición constitucional singular, que las reformas efectuadas conservan las decisiones políticas trascendentales a la par que han actualizado lo necesario del texto, que la idea de una renovación constitucional no representa el sentir general, y que no resulta prudente políticamente ni conveniente en época de crisis.

En mi opinión, hace mucho que la Constitución de 1917 no es un documento que exprese la voluntad del titular de la soberanía, ni proyecta la sociedad hacia un horizonte compartido por todos los mexicanos. Ha sido un documento en permanente proceso constituyente, como se ha expuesto, pero desde arriba, desde las élites políticas, desde los representantes de la soberanía, no desde el soberano. Así, la Constitución mexicana ha sido, en lo fundamental, un instrumento reproductor del status quo, conservador del andamiaje político.

La Constitución mexicana arriba a sus cien años y eso es motivo de jolgorio. Empero, anoto, la conmemoración adviene en un momento de crisis estructural del sistema político, condicionada por la incapacidad del Estado para cumplir algunas de sus funciones vitales, la desconfianza social hacia el gobierno y la percepción de deslegitimación moral de la clase política. Por ello, parejo a la celebración, debería efectuarse una reflexión crítica sobre el futuro de la nación mexicana, el valor de la Constitución como documento de los ciudadanos, y su rol transformador de la sociedad.

\footnotetext{
${ }^{38}$ Fix-Zamudio Héctor y Valencia Carmona, Salvador, Derecho constitucional mexicano y comparado, México, Porrúa, 2001, pp. 110-111.
} 


\section{Bibliografía}

Alcalá-Zamora, Niceto, La protección procesal internacional de los derechos humanos, Madrid, Civitas, 1975.

Andrea SÁnchez, Francisco José de, "La restauración de los tres pilares del constitucionalismo mexicano: el original sistema presidencial, el principio de no-reelección y el articulado de contenido social”, Boletín Mexicano de Derecho Comparado, vol. 1, México, Instituto de Investigaciones Jurídicas, 2008, pp. 1-13.

Atienza, Manuel, El sentido del derecho, Barcelona, Ariel, 2001.

Bernal Pulido, Carlos, "Refutación y defensa del neoconstitucionalismo", en, Miguel Carbonell (ed.), Teoría del neoconstitucionalismo. Ensayos escogidos, Madrid, Trotta - UnAM, 2007.

BIDART CAMPOS, Germán, El constitucionalismo en las postrimerías del siglo XX, México, Universidad Autónoma de México, 1988.

Biscarettidi RufFia, Paolo, Iintroducción al derecho constitucional comparado. Las

Formas de Estado y las Formas de Gobierno. Las Constituciones modernas. 1988-1990: un período de profundas transformaciones constitucionales en Occidente, en la URSS y en los Estados socialistas del Este europeo, México, Fondo de Cultura Económica, 2000.

Cappelletti, Mauro, "Justicia Constitucional supranacional. El control judicial de las leyes y la jurisdicción de las libertades a nivel internacional”, Revista de la Facultad de Derecho de México, No. 110, mayo-agosto, 1978, pp. 237 y ss. [Consultado 21 de febrero de 2016]. Disponible en: http://www.juridicas. unam.mx/publica/rev/indice.htm?r=facdermx\&tn=110

Carbonell, Miguel, Teoría del neoconstitucionalismo. Ensayos escogidos, Madrid, Trotta - UnAM, 2007.

Carbonell, Miguel. Neoconstitucionalismo(s), Madrid, Trotta - unam, 2007.

CÁRdenAs Gracia, JaIme, Transición politica y reforma constitucional en México, México, unAm, 1994.

Carpizo, Jorge, El presidencialismo mexicano, México, Siglo XXI, 2002.

CARPIZO, Jorge, "Reformas constitucionales al poder judicial y a la jurisdicción constitucional, del 31 de diciembre de 1994”, Boletín Mexicano de Derecho Comparado, No. 83, mayo-agosto, 1995, Nueva Serie, Año XVIII. [Consultado 12 de enero de 2016]. Disponible en: http://www.juridicas.unam.mx/ publica/rev/boletin/cont/83/el/el14.htm

Carpizo, JoRge. Concepto de democracia y sistema de gobierno en América Latina, México, Universidad Autónoma de México, 2007. 
Carrillo, Fernando. "La quijotada de la séptima papeleta”, Revista Cambio, No. 418, 21 de junio 2001. [Consultada 14 de junio de 2012]. Disponible en: https://fundacionseptimapapeleta.wordpress.com/acerca-de/

Colomer VidAl, Antonio, "El presidencialismo iberoamericano", en Memorias del IV Congreso Iberoamericano de Derecho Constitucional, México, Universidad Autónoma de México, 1992.

Comanducci, Paolo, "Formas de (neo)constitucionalismo: un reconocimiento metateórico", Isonomia, No. 16, abril 2002.

Comisiones Legislativas, LXI Legislatura, Congreso de la República, Reforma de Estado. [Consultado 10 de noviembre de 2015]. Disponible en: http://www. senado.gob.mx/comisiones/LX_Legislatura/reformadelestado/_

Cossío Díaz, José Ramón, Sistemas y modelos de control de constitucionalidad en México, México, unam, 2013.

Fernández Segado, Francisco, "La justicia constitucional ante el siglo xxi: la progresiva convergencia de los sistemas americano y europeo-kelseniano", Revista Pensamiento Constitucional, vol. 11, No. 11, Pontificia Universidad Católica de Perú, 2005, pp. 20-75.

Ferrajoli, Luigi, "Sobre los derechos fundamentales", en Miguel Carbonell (ed.), Teoría del neoconstitucionalismo. Ensayos escogidos, Madrid, Trotta - UnAm, 2007

Fix-Zamudio, Héctor y Valencia Carmona, Salvador, Derecho Constitucional mexicano y comparado, México, Porrúa, 2001.

Gargarella, Roberto, "El nuevo constitucionalismo latinoamericano. Algunas reflexiones preliminares”, Crítica y Emancipación, año 2, No. 3, Clacso, Buenos Aires, 2010, pp. 169-188.

Gargarella, Roberto y Courtis, Christian, El nuevo constitucionalismo Latinoamericano: promesas e interrogantes, Santiago de Chile, Cepal, 2009.

Giovanni, SARTori, Ingeniería Constitucional Comparada, México, Fondo de Cultura Económica, 1996.

Gross Espiell, Héctor, Las Constituciones del Uruguay, Madrid, Centro de Estudios Constitucionales, 1978.

LinZ, JuAn, "Democracia: presidencialismo o parlamentarismo: ¿Hace alguna diferencia?”, en Oscar Godoy (ed.), Hacia una democracia moderna. La opción parlamentaria, Santiago, Universidad Católica de Chile, 1990.

Loewenstein, Karl, Teoria de la Constitución, Barcelona, Ariel, 1998.

MARTínez DALMAu, RubÉn, "El proceso constituyente: la activación de la soberanía”, en Iñigo Errejón y Alfredo Serrano (coords.), ¡Ahora es cuándo, carajoi Del asalto a la transformación del Estado en Bolivia, España, Ediciones de Intervención Cultural, 2011. 
Nogueira Alcalá, Humberto, "Consideraciones sobre los tipos de gobierno presidencialista y semipresidencialista en la reforma constitucional”, Boletín Mexicano de Derecho Comparado, Número conmemorativo, sexagésimo aniversario, 1948-2008, mayo-agosto 2016, Universidad Nacional Autónoma de México, pp. 758 y ss.

Nohlen, Dieter, "Parlamentarismo vs. presidencialismo en América Latina. Dos enfoques contrapuestos”, en Dieter Nohlen y Mario Fernández Baeza, (eds.), El presidencialismo renovado: Instituciones y cambio politico en América Latina, Caracas, Nueva Sociedad, 1998.

Parejo Alfonso, Luciano, "Constitución y valores del ordenamiento constitucional y el ordenamiento jurídico”, en Compilación de textos para Seminario Internacional, Universidad de Alicante, 1997, p. 104.

Pietro Barcelona, El Estado y los juristas, Barcelona, Editorial Fontanella, 1976. Prieto-Sanchis, Luis, Justicia constitucional y derechos fundamentales, Madrid, Trotta, 2013.

SÁnchez Agesta, Luis, Curso de derecho constitucional comparado, Madrid, Universidad Complutense de Madrid, 1980.

Valadés, Diego, El control del poder en México, México, unam, 1988.

Viciano Pastor, Roberto y Martínez Dalmau, Rubén, "Los procesos constituyentes latinoamericanos y el nuevo paradigma constitucional”, Revista IUS, No. 25, Instituto de Ciencias Jurídicas de Puebla, México, 2010, pp. 7-29.

Viciano Pastor, Roberto y Martínez Dalmau, Rubén, "El nuevo constitucionalismo latinoamericano: fundamentos para una construcción doctrinal”, Revista General de Derecho Público Comparado, No. 9, 2011, pp. 1-24.

Viciano Pastor, Roberto, Estudios del nuevo constitucionalismo Latinoamericano, Valencia, Tirant lo Blanch, 2012.

Villabella Armengol, Carlos Manuel, "El derecho constitucional del siglo xxi en América Latina: entre la osmosis y un nuevo paradigma”, Revista El Otro Derecho, No. 48, Colombia, Instituto Latinoamericano de Servicios Alternativos, 2014, pp. 85-113.

Villabella Armengol, Carlos Manuel, El Nuevo constitucionalismo Latinoamericano: ¿Un nuevo paradigma?, México, Editorial Juan Pablo, 2014. 